\title{
A INSTITUIÇÃO: UM LUGAR DE PRODUÇÃO SOCIAL*
}

Julieta Beatriz Ramos Desaulniers**

SÍNTESE - O presente Artigo visa destacar como alguns representantes da Igreja Católica, em Porto Alegre/RS, através de um conjunto de ações e estratégias, promovem a institucionalização de um meio pedagógico que operacionaliza o novo discurso religioso, desencadeado em 1891, com a publicação da Encíclica Rerum Novarum: as escolas de ofício católicas voltadas às classes populares.
ABSTRACT - This present article aim to point out how some representatives of the Catholic Church, in Porto Alegre/RS, through a set of actions strategies, to promote the institucionalize of a pedalogical way that make it possible the new religious discourse, started in 1891, with the publication of the Encyclic Rerum Novarum: The catholic vocational schools, concerning the popular class.

\section{1 - Considerações iniciais}

O presente artigo visa destacar como alguns representantes da Igreja Católica, em Porto Alegre,RS, através de um conjunto de ações e estratégias, promovem a institucionalização de um meio pedagógico que operacionaliza o novo discurso religioso, desencadeado em 1891, com a publicação da encíclica Rerum Novarum: as escolas de ofício católicas voltadas às classes populares.

Estudos e pesquisas realizados desde 1988, com o intuito de reconstruir tal dinâmica, indicam a Pia União do Pão dos Pobres como sendo o caso exemplar dentre as demais escolas de ofício católicas da Capital e do Interior do Estado do Rio Grande do Sul. Por isso, as considerações feitas a seguir referem-se, especialmente, a essa instituição.

O Pão dos Pobres foi fundado em 1895 pelo cônego Marcellino Bittencourt para se constituir Abrigo para viúvas pobres e seus filhos. Em 1916, foi transformado em Orfanatrófio aos meninos carentes em regime de internato fechado, sob direção dos Irmãos Lassalistas.

Tal ruptura expressa uma radicalização de agentes da Igreja Católica de Porto Alegre quanto à formação dos segmentos populares, visando assim garantir e ampliar os limites de sua atenção frente aos vários setores sociais. Afinal, era a postu-

* Este texto refere-se a conteúdos desenvolvidos na Tese de Doutorado defendida em maio de 1993, UFRGS, que se intitula "Trabalho: a escola do trabalhador?". Foi apresentado no II Congresso Iberoamericano de História da Educação, realizado em Campinas - UNICAMP, SP, de 11 a 15-9-94.

** Professora do Instituto de Filosofia e Ciências Humanas e da Faculdade de Serviço Social da PUCRS.

\begin{tabular}{|l|l|l|l|l|l|}
\hline VERITAS & Por to Alegre & v. 40 & $\mathrm{n}^{2} 158$ & Junho 1995 & p. 235-242 \\
\hline
\end{tabular}


ra moralizadora que começava a se expandir com o desenvolvimento do processo industrial, ${ }^{1}$ exigindo a construção de identidades que garantissem maior rentabilidade ao trabalho, buscada também através de outras esferas da sociedade, além do espaço da indústria.

Em função disso, em 1924, um ano após os conflitos entre o partido do governo estadual do Rio Grande do Sul e seus opositores - liderados por Assis Brasil devido à reeleição de Borges de Medeiros para o seu quinto mandato, alguns anos após o fim da Primeira Guerra Mundial e apenas três anos depois do início da construção da Catedral Metropolitana de Porto Alegre, os Irmãos decidiram construir um novo espaço, com capacidade para abrigar mais de 250 órgãos. Ou seja, aumentar em cinco vezes as disponibilidades de acomodação do Orfanato Pão dos Pobres. Isso foi, sem dúvida, uma demonstração de força que se baseava, em grande parte, no apoio que os lassalistas supunham poder contar junto aos diversos segmentos da sociedade gaúcha.

Apesar das resistências do arcebisbo D. João Becker, a decisão de ampliar as bases materiais do Orfanatrófio, dando-lhe assim a aparência de um monumento, tornou-se realidade em apenas seis anos. Inúmeras iniciativas foram promovidas por comissões de "damas e cavalheiros" da elite porto-alegrense, criadas no lançamento da pedra fundamental, para angariar fundos à construção da obra. Desse modo, atraíram a comunidade através de consertos, festivais, rifas, torneios de futebol, sorteios com prêmios de grande valor e vários outros tipos de campanhas. Assim, em 1930, foram inauguradas as novas instalações que incluiam o Liceu de Artes e Ofício, devidamente equipado com maquinário moderno.

Sem dúvida, esse periodo foi importantíssimo para a institucionalização ${ }^{2}$ do Pão dos Pobres. As suas bases administrativas fortaleciam-se à medida que se articulavam aos interesses dos demais campos do espaço social, os mesmos que lhe asseguraram a edificação das bases materiais. Ambas, evidentemente - condições materiais e de gestão - realidades indispensáveis para formar filhos de parte da população mais carente de Porto Alegre e mesmo de outras regiões do Estado gaúcho, foram mantidas e até ampliadas no decorrer das seguintes décadas, por várias iniciativas implementadas pelos vários agentes envolvidos nesse processo, em especial pelos representantes do campo religioso - os Irmãos Lassalistas.

1 Essa questāo é abordada em profundidade na obra de PAGO, Margareth. Do Cabaré ao lar - a utopia de cidade disciplinar (Brasil 1890/1930). Rio de Janeiro, Editora Paz e Terra, 1985.

2 O Pão dos Pobres enquanto instituição, entendida aqui como um conjunto de relações sociais, impõe-se como unidade material e de gestão. $O$ estudo de tais dimensões constitui-se um preâmbulo à análise da formação nele instaurada, já que esse foi o espaço onde concretamente se produziu tal processo. A abordagem referente à instituição aqui utilizada baseia-se, fundamentalmente, nas concepções desenvolvidas por CHAPOUL.JE, J. Pierre e outros. Entre os seus estudos, cita-se CHAPOULWE, J. M. \& BRIAND, J. P., "Instituition Scolaire et lá Scolarisation: une perspective d'ensemble". In: Revue Française de Sociologie. Paris, Éditions CNRS, n XXXIV, 1993. 


\section{2 - A construção da imagem da obra "O Pão dos Pobres"}

Em 1930, o espaço de possibilidades ${ }^{3}$ do Pão dos Pobres estava, em grande parte, consolidado. Enfim, iniciava-se o tempo em que as ações e estratégias dessa "monumental obra de caridade", recém construída, dispunham efetivamente das bases necessárias para intensificar e consolidar o processo de formação desejado. Agora, o grande desafio era garantir os recursos necessários à subsistência de todos os órfãos, bem como a própria manutenção dos prédios e maquinários. Isso implicava, sem dúvida, criar e divulgar junto à sociedade civil novas concepções sobre a pobreza e sobre esses meninos "desvalidos da sorte". Ou seja, era necessário mobilizar o capital principal do campo em questão ${ }^{4}$ o capital religioso - e, assim, assegurar a instauração do novo discurso religioso através de um novo estilo de ação pedagógica.

Com a valorização do capital religioso, através da inculcação de um sistema de práticas e representações consagradas - valores, crenças e símbolos - "cuja estrutura (estruturada) reproduz sob forma transfigurada (irreconhecivel), a estrutura das relações econômicas e sociais vigentes", ${ }^{5}$ a obra do Pão dos Pobres e a própria Igreja local obtiveram maior legitimação.

Isso provocou uma mudança no habitus de parte da população de Porto Alegre, com relação a certos problemas sociais, convertendo o ethos em ética, através de "um conjunto sistematizado de normas explícitas", ${ }^{6}$ pelo qual se propunha uma nova forma de encarar a pobreza. $O$ apelo maior referia-se aos deveres de cada cristão face a essa realidade: era necessário concretizar o apoio, através de iniciativas de ajuda material, que objetivassem de alguma forma melhorar as condições de vida dos "filhos de Deus" socorridos pelo Pão dos Pobres.

O funcionamento desses dispositivos produziu um poder eclesial articulado ao poder leigo, dando organicidade e finalidade à obra do Pão dos Pobres. Iniciativas como festas e doações, eram rigorosamente catalogadas e divulgadas, prestigiando-se assim os representantes dos campos do poder e os doadores, numa demonstração de pleno inter-relacionamento da obra com a sociedade.

A instituição aumentava seu poder na medida em que fortalecia suas estruturas e, ao mesmo tempo, ampliava sua capacidade de estruturação ${ }^{7} \mathrm{O}$ que ocorreu foi uma transformação do capital religioso em outros capitais, obtidos junto aos demais campos, de modo a operacionalizar o novo discurso religioso, assegurando e expandindo o poder da Igreja.

3 Conforme Bourdieu, o espaço de possibilidades resulta da herança acumulada pelo trabalho coletivo que se apresenta a cada agente sob forma de alternativas práticas em todo ato de produção. BOUR- DIEU, Pierre. "Le Champ littéraire". In: Revue Actes de Ia Recherche en Sciences Sociales. Paris, Éditions de Minuit, $n^{2} 89$, set/1991, p. 36. (Trad. da autora).

4 O campo "constitui-se de forças, variando de acordo com as posições que os agentes ocupam e lutas de concorrência que tendem a conservar ou transformar o campo de forças." "... É a luta entre os agentes que faz a história do campo". In: "Le Champ Littéraire", Revue Actes de la Recherche en Sciences Sociáles. Paris, Éditions de Minuit, $\mathrm{n}^{\mathrm{Q}}$ 89, set/1991, p. 5 e 24. (Trad. da autora).

5 BOURDIEU, P. A economia das trocas simbólicas. São Paulo, Editora Perspectiva, 1987, p. 46.

6 Idem, p. 46.

7 BOURDIEU, Op. Cit., p. 30 (1991). 
Isso foi viabilizado devido à forma especifica de illusio - "incomensurável face aos interesses engendrados pelos outros campos ${ }^{18}$ - que produziu a imagem e 0 prestígio do trabalho desenvolvido no Pão dos Pobres, através das iniciativas dos seus diretores e professores Irmãos.

O interesse ou illusio, ${ }^{9}$ refere-se à instauração da crença quanto ao valor das ações e iniciativas de um dado campo e é, simultaneamente, condição de seu funcionamento, "na medida em que isso é o que estimula as pessoas, o que as faz concorrer, rivalizar, lutar, e o produto do seu funcionamento" ${ }^{10}$ Sendo assim, resulta "de uma determinada categoria de condições sociais". ${ }^{13}$

Sabe-se que uma dinâmica religiosa exerce o seu poder simbólico - "o poder de fazer coisas com palavras" e, assim, subsistir no tempo - na medida em que "consagra ou revela coisas que já existem", através dos fundamentos básicos que mobilizam a ação. ${ }^{12}$

Nessa perspectiva, o Pão dos Pobres procurou construir sua imagem, a fim de obter "o reconhecimento tácido ao valor da sua obra, ${ }^{13}$ lançando mão de seu principal recurso na disputa de espaço e poder: o seu capital simbólico, com conteúdo religioso.

Entre as principais ações em que os Irmãos mobilizavam o sagrado, recriando e aprofundando a fé dos membros da comunidade local, o símbolo que monopolizou tais iniciativas foi representado pela figura de Santo Antônio - o padroeiro da entidade, que foi explorada através de várias estratégias expostas a seguir.

\section{1 - O padroeiro Santo Antônio}

Designado padroeiro das coisas perdidas e das realizações quase impossiveis, a Santo Antônio eram atribuidos vários poderes, bastante propalados pelos fundadores e pelos continuadores do Pão dos Pobres.

Essas atribuições foram imediatamente associadas aos órfãos recolhidos por essa instituição, considerados seres "perdidos, desvalidos e abandonados pela própria sorte", assim como à formação que essa entidade lhes oferecia que, "quase por milagre" transformava-os em homens sadios, física e moralmente, para bem servir a eles e à Pátria.

Tal associação reforçou o significado e a importância do capital simbólico da instituição, o que lhe permitiu realizar os mais variados tipos de manipulação quanto aos poderes do Santo, envolvendo segmentos da comunidade, independente de faixa etária e status sócio-econômico. Em decorrência disso, criaramse inúmeros mecanismos para arrecadar fundos para o Pão dos Pobres, tais como:

8 BOURDIEU, Pierre, Repouses - pour une anthropologie réflexive. Paris, Éditions du Seuil. 1992. p. 92.

9 Observa-se que, mais recentemente, BOURDIEU prefere o emprego de illusio ou libido em lugar de interesse, para se referir aos mecanismos acionados pelo campo, com vistas à produção da crença quanto ao valor da obra. Mais detalhes In: BOURDEU, op. cit., p. 29, 30. (1992) (Trad. da autora). BOURDIEU, Pierre, Coisas ditas. São Paulo, Editora Brasiliense, 1990, p. 127.

11 Idem, p. 128.

12 Idem, p. 167.

13 BOURDIEU, op. cit., p. 93 (1992). 
- venda de velas aos fiéis, para pagarem as promessas alcançadas;

- comemoração de bodas de casamento, quando o casal oferecia uma doação ao santo casamenteiro;

- trezenas às terças-feiras, como oportunidade para dar esmola ao santo multimilagreiro;

- pagamento de promessas alcançadas: com o salário do mês, com parte de seus bens ou com uma oferenda, dada durante um certo período aos órfãos (roupas, presentes e alimento);

- datas de aniversários de morte, reverenciadas com uma doação a Santo Antônio, entregue ao Pão dos Pobres;

- promoção da grande festa anual - considerada a festa dos órfãos - em junho, em homenagem a Santo Antônio. ${ }^{14}$

\section{2 - O Boletim do Pão dos Pobres}

Além de propagar e produzir o valor da obra através da imagem de Santo Antônio, o Boletim tinha como principal finalidade, conforme os termos do seu editorial, "propagar a obra do Pão dos Pobres, angariar simpatias e adesões de contribuintes de nossa instituição; alentar e aumentar o número dos corações que, por amor a Nosso Senhor Jesus Cristo, exerçam a caridade no campo em que desabrocham as flores primaveris da vida humana". ${ }^{15}$

A partir desse objetivo de caráter suficientemente amplo, os temas mais diversos podiam ser abordados, desde que tivessem alguma relação com fatos, principios ou idéias da realidade social e se prestassem a veicular: o posicionamento da Igreja enquanto instituição universal, nacional e local; os principios fundamentais da religião católica; os principais pressupostos que guiavam as ações e empreendimentos da congregação lassalista, com algum destaque à comunidade do Pão dos Pobres.

Os apelos para angariar donativos eram repetidos de diversas maneiras, em muitas páginas de cada número do Boletim. Alguns trechos serão anotados abaixo, com o objetivo de ilustrar o que se comentou anteriormente:

- "Não vos esqueçais que um dos melhores modos de grangear as bênçãos de Deus e a proteção de Santo Antônio é auxiliar o Pão dos Pobres na manutenção dos órfãos que abriga, instrui e educa. ${ }^{16}$

- "Certa moça dessa capital fez interessante promessa a Santo Antônio e a cumpriu: se conseguisse um bom emprego daria todo o primeiro ordenado aos pobres órfãos de Santo Antônio. Com toda a generosidade já nos entregou os Cr\$ $10.000,00^{\prime \prime} .^{17}$

14 Os preparativos iniciavam meses antes, quando um casal festeiro, nomeado pela direção do Orfanotrófio, organizava e tomava as providências necessárias ao sucesso da promoção que oferecia: rifas, chás beneficentes, gincana, quermesse e vánias atividades em que os órfãos apresentavam suas habilidades na banda, no coral ou em peças de teatro. Os festejos duravam alguns dias, envolvendo a comunidade, desde os preparativos até o encerramento, como um meio certo de obtenção anual de recursos para a entidade, graças a Santo Antônio.

15 Editorial do Boletim do Pão dos Pobres.

16 Op. cit., ano XLI, $n^{2} 4$, set, out, nov/1950, p. 8.

17 Op. cit., ano LXI, $n^{\circ} 2$, abril, maio, junho/1958, p. 14. 
Com distribuição gratuita, desde a criação em 1898 até a data em que foi publicado o último número, em 1967, o Boletin teve uma circulação representativa: sua tiragem girava em torno de 4.000 a 5.000 exemplares, sendo publicado trimestralmente durante a maior parte da sua existência, com uma média de 20 a 30 páginas em cada edição.

Esses dados informam que a publicação exerceu um papel importantíssimo ao veicular a imagem da obra do Pão dos Pobres e, dessa forma, assegurou e expandiu a esfera de poder do espaço que representava: o campo religioso. Além disso, constitui-se em mais um agente a formar a opinião da sociedade civil sobre os aspectos de interesse do referido campo.

\section{3 - A imprensa local}

A imprensa sempre foi utilizada como meio de propagar e construir a imagem e o valor da obra, graças a sua importância e repercussão junto a comunidade porto-alegrense e às de outras regiões do sul do País.

Um dos aspectos que facilitava o acesso nos jornais, como a respectiva veiculação de notícias referentes a essa entidade, além do apoio e reconhecimento, era a presença neles de funcionários que tinham sido formados pelo Pão dos Pobres.

Longas matérias eram publicadas em jornais nas datas comemorativas da instituição. O seu conteúdo centrava-se na recapitulação da trajetória do empreendimento, destacando o seu pleno êxito em todas as iniciativas implantadas e o seu fim principal: o de prestar formação moral e profissional a órfãos carentes.

A finalidade era justificar o auxílio dos colaboradores, demonstrando que o resultado tinha sido um grande investimento; e, com base nessa lógica, expunha-se ao público leitor que as constantes dificuldades em manter tamanho número de órfãos eram superadas somente com o permanente apoio financeiro que, até aquele momento, tinha sido garantido pelos cidadãos caridosos, e dos quais esperavam continuar recebendo ajuda.

Sem dúvida, a imprensa foi um meio bastante utilizado pela instituição para que esta fortalecesse sua imagem e, assim, dispusesse de novos elementos e justificativas para os constantes pedidos de colaboração, a fim de que o Pão dos Pobres continuasse atendendo ao menor desprotegido e por esse meio garantisse seu espaço de poder junto aos demais setores sociais.

\section{4- Os benfeitores}

É possivel reconstituir aspectos importantes da trajetória dessa instituição, apenas estudando a atuação de alguns benfeitores, ${ }^{18}$ tamanha a sua importância na vida do Pão dos Pobres.

$\mathrm{Na}$ condição de representantes dos principais campos do poder, os benfeitores exerceram um papel importante na instauração do sistema de crenças que o Pão dos Pobres utilizou como dispositivo para se relacionar com os vários setores so-

18 Conforme PARGAGNANI, "é conferido o Diploma de Benfeitor a quem, através de doações, auxilios de vulto, trabalhos, colaborações, etc., preste relevantes serviços à Congregação e a suas obras". In: JACOB, J. Biografias - afilhados e benfeitores dos Irmãos Lassalistas no Brasil (1907-1987). Canoas, Tipografia e Editora La Salle. 1988, p. 7. 
ciais e obter os recursos econômicos necessários à manutenção da obra. Mas, em troca, essa dinâmica prestigiou os benfeitores, dotando-os de poder moral e administrativo, o que significou uma certa reorganização de forças junto ao campo do poder e do campo religioso.

O fato de os benfeitores se envolverem diretamente com aspectos relativos à subsistência da entidade dava-lhes a chance e mesmo o direito de interferirem na própria gestão do Pão dos Pobres. Aliás, eles tinham o consentimento e a delegação para tal, concedidos pelo próprio arcebispo ou pelo irmão diretor.

Algumas promoções eram regulares e de responsabilidade dos benfeitores, como a festa de Santo Antônio, as formaturas, A festa de São Roque, o Natal, as madrinhas. Ainda, os benfeitores acompanhavam o irmão diretor em datas comemorativas da entidade, numa verdadeira peregrinação pelas casas de comércio, bancos e órgãos públicos, quando pediam doação e apresentavam o livro dos benfeitores da obra, para que o doador deixasse ali registrado o valor da sua colaboração e assinatura.

Face a essa constante presença e participação dos benfeitores no espaço do Pão dos Pobres, parece não ser difícil admitir que os mesmos exerceram uma influência considerável na gestão do empreendimento, durante todo esse período, especialmente no tocante às questões de ordem financeira e, em alguma medida, aos aspectos administrativos. A área de atuação restrita dos irmãos e representantes da sua hierarquia foi a das atividades pedagógicas, de formação dos órfãos, mesmo que, indiretamente, com as influências do campo de poder.

\section{5 - Outros meios de propagação do Pão dos Pobres}

Outros elementos que representavam simbolicamente as principais razões e existência dessa instituição eram periodicamente ritmados, para manter vivos os dispositivos geradores da fé e das doações: os próprios órfãos abandonados, as oficinas que os preparavam para se tornarem trabalhadores e os irmãos, que garantiam uma formação integral desses asilados, com base em sólidos princípios da religião católica.

Essas bases do Pão dos Pobres - produtores de "homens úteis a si e à sociedade" - eram devidamente explorados a fim de moralizar seus contribuintes não só através da imprensa, mas também por meio de outros mecanismos que exploravam diretamente seus principais símbolos, através de:

- visitas a autoridades com um grupo de órfãos, acompanhados por um irmão da administração;

- convites oficiais a vários poderes instituídos para visitarem a instituição;

- passeios pela cidade com os órfãos de fardamento impecável para mostrar "à comunidade os préstimos da obra";

- apresentação pública dos órfãos na Igreja, situada na área da escola;

- exposições com os trabalhos produzidos pelos internos;

- formatura - o momento solene em que a instituição devolvia ao convívio social parte de seus órfãos, agora com "uma formação cristã e aptos para o trabalho que lhe garantiria uma vida útil a si e a Pátria". ${ }^{19}$

19 Essa era uma frase reconente nos discursos proferidos nessas ocasiões, tanto pelos representantes dos Irmãos ou da Arquidiocese, como pelo representante da comunidade em geral. 
Assim, verificou-se a manutenção de um processo histórico de crenças, regularmente "lubrificado" nas suas engrenagens. O mecanismo desencadeador da produção do capital econômico, de que o Pão dos Pobres necessitava para se consolidar foi obtido através da conversão do capital caracteristico do campo religioso, assumia diversas formas, a seguir indicadas: contribuições mensais, heranças, subvenções, bolsas de estudos, livraria, maquinário para as oficinas, aluguéis provenientes dos imóveis adquiridos pela obra com os vários tipos de doações que recebia. Desse modo, obteve a ampliação do seu patrimônio, que lhe assegurou uma relativa autonomia face aos demais setores sociais com que interagia, no espaço de Porto Alegre e mesmo no Rio Grande do Sul.

Mas, com a deterioração do capital religioso - cada vez menos valorizado pelos diferentes segmentos sociais no decorrer do tempo o Pão dos Pobres, durante a década de 60, começou a viver os primeiros sinais de declínio. Como bem alerta Bourdieu, a trajetória de cada campo está inscrita, a cada momento, em sua própria estrutura e nas relações com os demais campos. ${ }^{20}$

\section{3 - Considerações finais}

Os Irmãos Lassalistas ligados ao Orfanatrófio, exerceram uma ação simbólica junto ao campo do poder e à sociedade civil, através da manutenção renovada de um sistema de crenças, que acabou gerando um habitus, fundado na responsabilidade participativa frente aos órfãos pobres. Nesse processo, agentes de vários campos foram envolvidos em favor da manutenção infra-estrutural da obra do Pão dos Pobres.

Em outros termos, os representantes dos campos do poder encontravam no próprio discurso religioso um respaldo para suas ações, e a Igreja, por sua vez, desempenhava, através dessa obra, uma de suas principais funções - justificar o status quo. Essa harmonia de interesses, em torno do Pão dos Pobres - responsável pela grande expansão da obra - é reveladora da importância e do significado do capital religioso ${ }^{21}$ ai mobilizado durante décadas.

Essa dinâmica, baseada nos pressupostos da Igreja Católica e associada a questões sociais, foi acionada com a mobilização de uma série de mecanismos e estratégias, os quais eram ritmados e repetidos sintematicamente. Isto gerou a construção de uma imagem consagrada e reconhecida, a ponto de a obra do Pão dos Pobres constituir-se un porta-voz dos órfãos abandonados.

Assim, as possibilidades para se desenvolver e consolidar a formação instaurada nesse meio operacional foram garantidas durante várias décadas. O processo de institucionalização do Pão dos Pobres baseado nessa dinâmica, perde 0 seu vigor no decorrer do tempo e entra em declínio. No entanto, enquanto um lugar ${ }^{22}$ de produção do social, a obra vai assumindo, após 1970, outras configurações.

20 BOURDIEU, p. 40. (1990).

21 BOURDIEU, op. cit., p. 48 e 58 (1987).

22. A categoria lugar é concebida aqui de acordo com a abordagem de Viñao. Considera que "Cualquer actividad humana precisa un espacio y un tiempo determinados". "La ocupación del espacio, su utilización, supone su constitución como el lugar. El 'salto cualitativo' desde el espacio al lugar, es, pues, una construcción". In: VIÑAO FRAGO, Antônio. "Del espacio escolar y la escuela como lugar: propuestas e cuestiones". p. 1 (mimeo, gentilmente cedido pelo autor). 